\title{
Théories et ruses du quotidien: Bucarest 1980
}

\section{Marta Caraion}

\section{OpenEdition}

Journals

Édition électronique

URL : http://journals.openedition.org/edl/2322

DOI : $10.4000 /$ edl.2322

ISSN : 2296-5084

\section{Éditeur}

Université de Lausanne

\section{Édition imprimée}

Date de publication : 15 mars 2020

Pagination : 27-32

ISBN : 978-2-940331-73-4

ISSN : 0014-2026

\section{Référence électronique}

Marta Caraion, "Théories et ruses du quotidien: Bucarest 1980 », Études de lettres [En ligne], 312 | 2020, mis en ligne le 24 mars 2020, consulté le 17 septembre 2020. URL : http:// journals.openedition.org/edl/2322 ; DOI : https://doi.org/10.4000/edl.2322 


\section{THÉORIES ET RUSES DU QUOTIDIEN : BUCAREST 1980}

Jadis les philosophes écartaient le quotidien du savoir et de la sagesse. Indispensable et vulgaire, les philosophes le jugeaient indigne de la pensée [...]. La situation a changé. En 1980, la Société suisse de philosophie a organisé un symposium européen autour du thème "le quotidien et la philosophie", au cours duquel il devint manifeste que la philosophie se définit aujourd'hui par son rapport au quotidien, par sa capacité à le saisir, à le comprendre, à l'intégrer dans un ensemble conceptuel visant la totalité et l'universalité ${ }^{1}$.

Lorsqu'il publie, en 1981, le dernier tome de sa trilogie Critique de la vie quotidienne (1947, 1961, 1981), Henri Lefebvre a le sentiment d'avoir rempli une mission commencée au sortir de la guerre et qui en était encore à l'état de programme: "nous déclarons la vie quotidienne objet de la philosophie", lançait-il dans La vie quotidienne dans le monde moderne (1968). Le mystérieux symposium suisse de 1980 est l'occasion, pour Lefebvre, de dater la conciliation de la philosophie et du quotidien, sur la base - prêtons attention à la formule - d'une perspective critique "visant la totalité et l'universalité» («la quotidienneté est un concept» permettant de connaître «la globalité sociale», affirmait-il dans son texte de 1968, p. 58 sq.). De cette ambition de conceptualisation totalisante, en surplomb, 1980 sonne aussi la fin, ou plutôt le moment de transition d'une pensée du monde matériel cherchant à s'affirmer comme sujet théorique (au risque de dématérialiser cette matérialité qu'elle cherche à définir) vers une pensée des pratiques et des usages, soit une théorie par le faire.

I. H. Lefebvre, Critique de la vie quotidienne, t. III, p. 9. 
Pendant que Lefebvre se prépare à clore sa prospection philosophique, Michel de Certeau avec Luce Giard et Pierre Mayol font paraitre, dans la collection 10/18, les deux volumes de L'invention du quotidien - 1. Arts de faire; 2. Habiter, cuisiner-, démarche de théorisation "au ras du sol», qui abandonne ouvertement la vision globale, panoramique, la perspective de maîtrise, "le plaisir de "voir l'ensemble", de surplomber, de totaliser", l'" exaltation d'une pulsion scopique et gnostique", cette "fiction de savoir» (p. 140), pour plonger dans la matière singulière du quotidien: "C'est "en bas" au contraire (down), à partir des seuils où cesse la visibilité, que vivent les pratiquants ordinaires de la ville» (p. 141) ${ }^{2}$. Une nouvelle pensée théorique éclot, basée sur une démarche de microobservation des pratiques ordinaires et des menus gestes de la consommation compris comme instaurateurs de cultures parallèles, illégitimes, qui subvertissent les normes et les structures officielles de production et qui échappent par ailleurs aux habitudes intellectuelles de l'investigation académique. Soucieux de se dégager de toutes les idéologies et de ne pas évaluer les pratiques de la consommation selon les grilles préconçues des discours productivistes (de l'économie de marché) ou du militantisme anti-productiviste, absorbées par le souci des grandes structures et inattentives au potentiel d'invention des usages des individus et des groupes, Certeau veut "analyser les pratiques microbiennes, singulières et plurielles» (p. 145) qui élaborent, contre les stratégies normatives, des tactiques buissonnières.

De cette "histoire [qui] commence au ras du sol, avec des pas" (p. 147), je propose un déplacement focal, un récit d'application: je serai, le temps d'une digression réflexive, «l'homme ordinaire», «l'anonyme rieur" (p. 14) dont Certeau questionne les "mille manières de "faire avec" " (p. 50). Au moment où L'invention du quotidien affiche ses options critiques, la Roumanie communiste expérimente de manière intense la friction, au quotidien, entre une "administration panoptique» et la "proliférante illégitimité» (p. 145), le grenouillage des vies ordinaires vouées aux arrangements furtifs avec la réalité. Alors que débutent les traumatiques démolitions des vieux quartiers de Bucarest et que les trajectoires invisibles des piétons s'égarent désormais dans les chantiers mégalomanes de Ceaușescu dont l'ambition est de s'offrir l'avenue la plus

2. M. de Certeau, L'invention du quotidien. 1. Arts de faire, 1980. Toutes les citations sont tirées du t. 1 de l'éd. Folio Essais. 
large d'Europe et le plus grand palais, mon horizon culturel est partagé entre un versant d'idéologie théorique qu'il est possible, par la routine scolaire, de résumer ainsi :

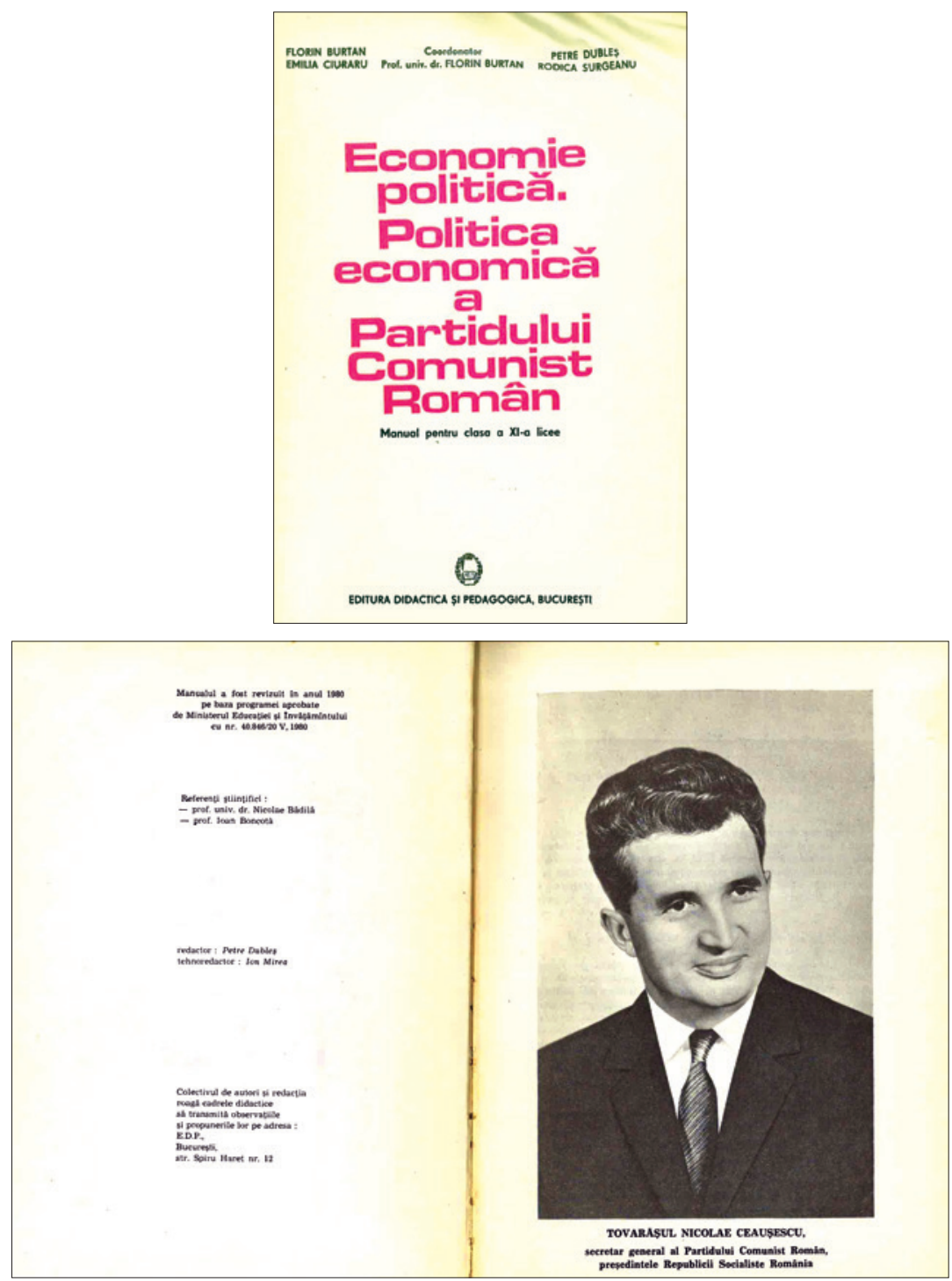

Page de titre intérieure et double page suivante tirées de Florin Burtan et al., Economie politică. Politica economică a Partidului Comunist Român. Manual pentru clasa a XI-a, București, Editura Didactică si Pedagogică, 1980. 
et des pratiques de l'existence matérielle déployant des prodiges de créativité à verser comme témoignage - à défaut de pouvoir en faire, rétrospectivement, un terrain d'investigation - au dossier de "l'invention du quotidien ». Comment circule, en 1980, le piéton de Bucarest, lui qui a vu son territoire urbain bouleversé par le tremblement de terre de 1977 et qui, pour peu qu'il habite la ville ancienne, faite de maisons basses et de cours ombragées, craint non seulement de se perdre, mais de perdre son habitat, au profit d'un petit cube dans une barre d'immeubles quelque part dans une banlieue de gravats? Comment construit-il le récit de cet espace bouleversé, "cette narrativité délinquante» (p. 191) que Certeau définit comme une culture de la résistance?

Alors que se termine, sans que je le sache encore, la dernière année de ma vie en Roumanie, le repas de Nouvel An 1980 se passe à chuchoter fébrilement des rumeurs formidables sur Solidarność: bribes à peine audibles d'un discours qui fantasme une résistance ouverte et qui, plus que tout autre dans l'Europe démocratique des enquêtes de Certeau, "a pour caractéristiques ses ruses, son effritement au gré des occasions, ses braconnages, sa clandestinité, son murmure inlassable» (p. 53). Et, au même repas de Nouvel An, alors que je connais par cœur, comme tous les élèves du pays, uniformément endoctrinés, les chapitres «Essence et formes de l'exploitation capitaliste", "Le capitalisme monopolistique " et "Crise générale du capitalisme» du manuel d'Économie politique et Politique économique du Parti Communiste Roumain (1980), j'apprends l'extraordinaire existence, dans la société de consommation impérialiste capitaliste, de yaourts aux arômes variés, chocolat, vanille, fraise, banane, noisette, et c'est tout l'ordre de mon monde communiste qui se trouve subitement subverti. Si la "production rationalisée, expansionniste, centralisée, spectaculaire et bruyante» (p. 53), incarnée par le yaourt industriel, peut devenir, en se transformant ainsi en récit clandestin, l'élément déclencheur d'une conscience politique, c'est bien par une de ces "tactiques traversières" (p. 51) qui inversent sans exception les logiques des pouvoirs de tous bords.

Ces détournements infimes, qui configurent, à l'Est de l'Europe, toute la contre-culture des décennies d'avant 1989, laissent peu de traces concrètes, égrenés seulement en récits innombrables. Certeau interroge, dans le chapitre intitulé «Le temps des histoires», la "narrativité» intrinsèque des pratiques ordinaires, insaisissables hors d'une étude de l'articulation entre récits et mémoire collective. Et pendant qu'il élabore une 
théorie conjointe des pratiques et des récits, Perec et Bober confrontent, à Ellis Island, les traces matérielles de millions d'immigrés avec les témoignages de quelques survivants: à la suite de leur film, Récits d'Ellis Island, histoires d'errance et d'espoir, livre des exils, est publié en 1980. "Comment lire ces traces? [...] Comment retrouver ce qui était plat, banal, quotidien, ce qui était ordinaire, ce qui se passait tous les jours?" (p. 37), se demande Perec qui parvient, en somme, à la même conclusion que Certeau: la nécessité du récit pour accéder à l'expérience commune. Pendant ce temps, ma trajectoire s'apprête à se dérouter brusquement en prenant la direction de l'exil au pays des yaourts.

Et après?

En 1981, je m’installe en Suisse comme réfugiée politique. À Bucarest, l'éléphantesque Maison du Peuple s'achèvera quelques années après la chute du régime communiste et la mort du dictateur, en 1989; elle est actuellement le centre des circulations moutonnières des touristes. Perec, dont la pensée du quotidien a été imprégnée par les écrits de Lefebvre, développera la notion, devenue virale, d'infra-ordinaire. Le philosophe Dagognet proposera une nouvelle orientation pour théoriser les matérialités ordinaires; en même temps émerge, dans les années 1980, le vaste champ des études de culture matérielle.

\section{Marta Caraion}

Section de français et Formation Doctorale interdisciplinaire, Faculté des lettres, Université de Lausanne 


\section{BIBLIOGRAPHIE}

Burtan, Florin et al., Economie politică. Politica economică a Partidului Comunist Român. Manual pentru clasa a XI-a, București, Editura Didactică si Pedagogică, 1980.

Certeau, Michel de, L'invention du quotidien. 1. Arts de faire. 2. Habiter, cuisiner (1980), Paris, Gallimard, 1990 et 1994.

Dagognet, François, Éloge de l'objet: Pour une philosophie de la marchandise, Paris, Vrin, 1989.

—, Rematérialiser: matières et matérialismes, Paris, Vrin, 1989.

Lefebvre, Henri, Critique de la vie quotidienne, t. I, Paris, Grasset, 1947, 2e éd. augmentée: Paris, L’Arche, 1958; t. II et III, Paris, L'Arche, 1961 et 1981.

—, La vie quotidienne dans le monde moderne, Paris, Gallimard, Idées, 1968.

Perec, Georges, L'infra-ordinaire, Paris, Seuil, 1989.

Perec, Georges, Bober, Robert, Récits d'Ellis Island, histoires d'errance et d'espoir (1980), Paris, P.O.L., 1994. Film: INA, 1979, diffusé en novembre 1980. 